\title{
Real-Life Incentives Driving Public-Private Partnership in Diagnostic Services
}

\author{
Akram Baniasadi ${ }^{1}$, Ali Akbari Sari ${ }^{2}$, Abbas Rahimi Foroushani ${ }^{3}$, Mehdi Jafari \\ Sirizi $^{4}$, Ebrahim Jaafaripooyan ${ }^{5 *}$
}

\section{OPEN ACCESS}

Citation: Akram Baniasadi, Ali Akbari Sari, Ebrahim Jaafaripooyan' Mehdi Iaafari Sirizi, Abbas Rahimi Foroushani. Real-Life Incentives Driving PublicPrivate Partnership in Diagnostic Services. Ethiop J Health Sci. 2020;30(3): 409.doi:http://dx.doi.org/10.4314/ejhs.v30 i3. 12

Received: May 13, 2019

Accepted: December 31, 2020

Published: May 1, 2020

Copyright: (C2020 Akram B., et al. This is an open access article distributed under the terms of the Creative Commons Attribution License, which permits unrestricted use, distribution, and reproduction in any medium, provided the original author and source are credited.

Funding: Tehran University of Medical Sciences?

Competing Interests: The authors declare that this manuscript was approved by all authors in its form and that no competing interest exists.

Affiliation and Correspondence:

${ }^{1} \mathrm{PhD}$ Candidate of Healthcare Management, Department of Health Management and Economics, School of Public Health, Tehran University of Medical Sciences, Tehran, Iran

${ }^{2}$ Professor, Department of Health Management and Economics, School of Public Health, Tehran University of Medical Sciences, Tehran, Iran

${ }^{3}$ Professor, Department of Epidemiology and Biostatistics, School of Public Health, Tehran University of

Medical Sciences, Tehran, Iran

${ }^{4}$ Associate Professor, Department of Health Care Management, School of Health Management and Information Sciences, Iran University of Medical Sciences, Tehran, Iran

${ }^{5}$ Associate Professor, Department of Health Management and Economics, School of Public Health, Tehran University of Medical Sciences, Tehran, Iran

*Email: jaafaripooyan@tums.ac.ir

\section{ABSTRACT}

BACKGROUND: Diagnostic services are highly critical in the success of treatment processes, overly costly nonetheless. Accordingly, hospitals generally seek the private partnership in the provision of such services. This study intends to explore the incentives owned by both public and private sector in their joint provision of diagnostic services under the public-private partnership agreement.

METHOD: A qualitative, exploratory study was employed in Tehran hospitals from October 2017 to March 2018. Around 25 face-to-face, semi-structured interviews were conducted with the purposively recruited hospital managers, heads of diagnostic services and managers of private companies. Interviews were transcribed and analyzed using conventional content analysis, assisted by "MAXQDA-12".

RESULTS: Three main categories and nine sub-categories represented the incentives of public sector, and four main categories and seven sub-categories signified those of private sector. The incentives of public sector included the status-quo remediation, upstream requirements, and personal reasons. As such, the individual, social and economic incentives and legal constraints were driving the behavior of the private sector. CONCLUSIONS: Financial problem and gain were the most noted incentives by the partners. Attention to the either side's incentives and aims is likely to ensure the durability and effectiveness of such partnerships in the health sector.

KEYWORDS: Public-Private Partnerships, diagnostic Services, Hospital, Incentives, Iran

\section{INTRODUCTION}

Hospitals provide a wide range of services to meet their commitments to society, including diagnostic and clinical support services (1). In developing countries, approximately $5-15 \%$ of hospital expenditure is spent for purchasing advanced diagnostic equipment (2-3). However according to WHO, more than $38 \%$ of medical equipment are out of service (4) and of which $39 \%$ is because of users' poor expertise. As such, $50-80 \%$ of this resource wastage is due to the improper use and inappropriate

DOI: http://dx.doi.org/10.4314/ejhs.v30i3.12 
technical repair (5-8). According to the recent studies, $75 \%$ of complaints against radiologists are about wrong diagnosis (9-10), mainly because of poor technique or poor image quality (11-14). Moreover, $44 \%$ of all medical errors in health systems are arising from error in diagnostic tests specially conducted by laboratories (15-16). The main causes of diagnostic medical errors are mentioned as non-standard equipment (17-18), lack of experience and expertise, high workload (19-20) and poor system related factors (9).Therefore, the precision and cost of diagnostic services in a way could be interpreted as the reliable indicators of provided medical care effectiveness and efficiency (21-23).

Public private partnership (hereafter PPP) approach is claimed to have a significant effect on the efficiency and service quality in healthcare (21, 24). It has thus turned into an influential strategy of governments to improve the quality of services (25).

However, there are many partnerships that might face challenges, need renegotiation, and might not continue or are likely to stop sooner than expected (15). Inconsistency of approaches, perspectives and incentives followed by each sector is against the tenet of PPP which requires the collaborations among groups for activities ought to be in line with the shared and mutually agreed objectives (26).

Generally, studies have illustrated several goals for the public sector to participate in the various health services with private sector in the form of PPP: improving service quality $(5,11-13)$, gaining knowledge and management skills $(11,15)$, recruiting professional staff (16), using private finance and management capabilities (17). The private sector also owns such incentives as the acquisition of a new market, increased future profits (11,115), reputation, legal mandates (11), and sustainable demand (17).

A significant proportion of PPP studies are related to the prevention and control of AIDS and tuberculosis $(18-19,21,23)$, the management of cancer and kidney diseases (24,27-28) and very few to the incentives of public and especially private sector for delivering diagnostic services collaboratively. According to the key role of partners' goal alignment in the success of partnership, this study intends to explore the goals and incentives owned by the public and private sector in providing diagnostic services under PPP agreement. It seeks to ultimately maximize the efficiency and effectiveness of PPP projects via optimizing these goals and motivations.

\section{MATERIALS AND METHODS}

Data collection and analysis: Around 25 face-toface, semi-structured interviews were conducted in Tehran hospitals in 2018 with a range of purposively recruited hospital managers, heads of diagnostic services, the directors of related private companies, the hospitals outsourcing experts and authorities (Table1). The interviews lasted for 90 minutes on average. The interviews were transcribed verbatim and analyzed using conventional content analysis (29), assisted by "MAXQDA-12". The authors reviewed the transcripts many times to gain the general understanding. The codes were extracted by 2 members of the research team with no conflicts of interest. They were categorized and reduced until shaping two main groups of incentives for public and private sector towards PPP.

Table 1: demographic information of participants

\begin{tabular}{|c|c|c|c|c|c|c|c|c|}
\hline \multirow[b]{2}{*}{ ב.: } & \multirow[b]{2}{*}{ 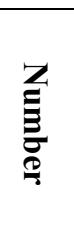 } & \multicolumn{2}{|c|}{ Sex } & \multicolumn{3}{|c|}{ Experience } & \multicolumn{2}{|c|}{ Education } \\
\hline & & $\frac{3}{0}$ & $\begin{array}{l}\overline{0} \\
\stackrel{0}{0} \\
\frac{\hat{\theta}}{0}\end{array}$ & 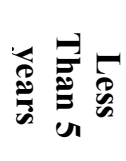 & 兽 & 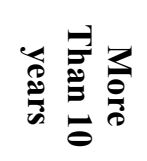 & 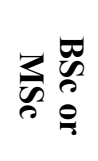 & 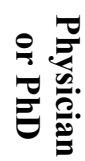 \\
\hline Public Sector* & 15 & 9 & 6 & 1 & 5 & 9 & 9 & 6 \\
\hline Private Sector & 9 & 7 & 2 & 2 & 3 & 4 & 8 & 1 \\
\hline Total & 25 & 16 & 9 & 4 & 8 & 13 & 18 & 7 \\
\hline
\end{tabular}

*-including PPP managers and supervisory team, experts, and hospital managers

DOI: http://dx.doi.org/10.4314/ejhs.v30i3.12 
Trustworthiness: The rigor of qualitative data and research was guaranteed through the continuous examining of data, adopting a team approach for data analysis and evaluation. As such, the emerging codes were also verified both through peerchecking and member-checkers. In fact, the transcribed text and preliminary categories were sent to the participants and their comments were sought.

Ethical issues: Ethical clearance for research was obtained from "Ethics Committee of Tehran
University of Medical Sciences" (Approval Number: IR.TUMS.REC.1394.824). The participants' name and their organizational affiliation remained confidential, to observe the ethical issues.

\section{RESULTS}

The incentives underlying PPP could be divided into two main categories including the public and private sector incentives (Table 2).

Table 2: Incentives of the public and private sectors in PPP of diagnostic services.

\begin{tabular}{|c|c|c|}
\hline Sectors & Main Incentives & Specific Incentives \\
\hline \multirow{3}{*}{ 吾 } & $\begin{array}{l}\text { Status-quo } \\
\text { remediation }\end{array}$ & $\begin{array}{l}\text { Efficiency improvement; Quality of services; Increasing } \\
\text { profitability; Shortage of human resource, Hospital financial } \\
\text { problems; Hospital managerial problems; Poor capacity in } \\
\text { medical equipment management }\end{array}$ \\
\hline & $\begin{array}{l}\text { Upstream } \\
\text { requirements }\end{array}$ & Government downsizing-regulations \\
\hline & Personal reasons & Unethical and unprofessional issues/relations \\
\hline \multirow{4}{*}{ ב.ּ. } & Individual factors & CV promotion; Personal interests \\
\hline & Social motivations & Serving people (social responsibility); Spiritual Satisfaction \\
\hline & Economic incentives & $\begin{array}{l}\text { Increasing profitability; Further participation options in the } \\
\text { future }\end{array}$ \\
\hline & Legal constraints & $\begin{array}{l}\text { Limit on licensing for some diagnostic services (leverage and } \\
\text { limit on licensing) }\end{array}$ \\
\hline
\end{tabular}

\section{PUBLIC SECTOR INCENTIVES}

Status-quo remediation: The poor management of current financial, administrative and executive affairs of hospitals was understood as a key incentive for attracting the private sector participation in the provision of diagnostic services.

Efficiency improvement: The hospitals' financial problems, weaknesses, constraints, and their inability to reduce the costs, on one hand, and allegedly high efficiency of private sector, on the other, were found to be the initial motivation for public officials to opt for PPP. "In most cases, especially in terms of the efficiency the private sector performance was better than us, in terms of money. But in the public sector, the only thing that is not cared about is money. "(No. 1)

However, some participants criticized the use of partnership as a first solution. "Inefficiency of processes should not be the only reason for partnership. Unfortunately, they just want to choose this method without any preliminary assessments. First, they should make some changes, if didn 't work, then go for partnership." (No. 2)

Quality of services: Given the high load of patients referred to the diagnostic units in the public hospitals and their poor control and order, using PPP was expected to lead to a better service coordination and quality. "According to the complaint forms, patients were unsatisfied with the

DOI: http://dx.doi.org/10.4314/ejhs.v30i3.12 
current lab services, so we considered some requirements for the contractors ...." (No. 3)

Increasing profitability: Diagnostic units are often more profitable than other hospital services and their revenues are used to manage other departments such as clinics. Hence, they are paid special attention by hospital managers. "Nowadays hospital managers' are more business minded, and attuned largely towards private sector attitudes. Whilst in the past just good service delivery was their main concern."(No. 1)

Shortage of human resources: Human resources could play a significant role in advancing the goals of organizations. The issues which have been mentioned by the interviewees were mainly about the lack of manpower and the hospitals' inability to recruit new staff, as well as, the inefficiency of current employees. "According to the Ministry of Health's announcement, while some personnel also retire, we are not allowed to recruit new personnel. Staff shortage forces us to accept partnership."(No. 5)

Hospital financial problems: The financial problems of hospitals and their subsequent inability to manage their diagnostic services were a frequent answer by the hospitals for seeking PPP. Delay of insurance reimbursement to the hospitals has deteriorated the situation. "... Insurance companies' payment to us has decreased. If we could get hold of our money, I could manage my lab efficiently."(No. 6)

Hospital managerial problems: A large number of respondents considered the managerial problems faced by hospitals as the key reasons behind the public sector's orientation towards PPP, including the inability and weakness of public sector in the optimized management of manpower, personnel compensation, medical equipment maintenance, accountability and performance management and customer-centeredness.

"The reason we contract out is the fact that a private partner is easily and quickly able to equip our units without being affected by any governmental bureaucracy. But in public systems many people should approve on it and it take months in some cases. " (No. 4)

Weak/poor capacity in medical equipment management: The old-fashioned and timeworn medical equipment and the imposed high costs on the hospitals and difficulty of quick replacement have led some hospitals to work together with the private sector to remedy their medical equipment weaknesses. "Our imaging equipment is outdated. The devices were not digital and films and drugs were rare and expensive, and this put hospital in trouble. We had many problems to find radiology film, besides we didn 't have affordability to update them." (No. 7)

Upstream requirements: The government's downsizing regulations, law enforcement for privatization and the headquarters' demand at the same way force the hospitals to seek partnership agreements.

Government's downsizing-regulations: In line with the Constitution, article 44, and the fifth development plan on decreasing the governmental incumbency, especially with the existing financial constraints and the high cost of diagnostic equipment, the participants believed that the hospitals can also benefit from the private sector capital. "The Office of Economic Participation in the Ministry is also seeking to get the body of the government smaller and increase the quality of services via private sector engagement."(No. 4)

As such, the universities oblige the hospitals to use private sector partnership as they seek to show their alignment with the ministry, in a way that they sometimes enter into a race with others without thinking of the outcomes. "At the beginning of PPP in the health sector, in order to outsource $10 \%$ of services, sonography of hospital $X$ was assigned to Dr.? ... . After a while, they noticed his report has conspicuous mistakes. Since, the contract was non-technical and has been in a hurry, after years still he is working and university is unable to terminate the contract."(No. 5)

\section{PERSONAL REASONS}

Some interviewees believed that the reason for choosing participatory methods is not only based on the rational and evidence-based reasons, but on the authorities' personal intentions: "For starting $a$ partnership with a private sector, the reason is not really seen right away. It is based on director's desire rather than other logical reasons. Personal problem of hospital manager with radiology supervisor was the main reason to outsource it." (No. 8)

DOI: http://dx.doi.org/10.4314/ejhs.v30i3.12 


\section{PRIVATE SECTOR INCENTIVES}

Individual factors: Some of the contributors considered individual factors as one of the incentives and motivations that have led them to invest in the public sector facilities.

Resume promotion: A number of public sector respondents suppose that one of the motivations of the private sector to participate is simply having an experience of partnership with a reputable university or hospital in their resume. Additionally, according to the public sector managers, a group of other private sector novice and newcomer participants, by having cooperation with academic centers in their CVs, are willing to ignore their short-term profits with the hope of gaining longterm profits. For this reason, they accept partnership with minimum profit and sometimes even with loss. "Those who are in their first year, usually offer good suggestions to the centers for doing so, which will make a resume for themselves later. They believe if they can start a partnership even with losses and have it in their resume; it is more likely to win next bids in the future." (No. 2)

Personal interests: Participants in the private sector considered personal interests as one of the reasons for employing participatory methods in service delivery: "Everyone has a job and interest. I could invest in buying and selling a car or building apartment; I could invest in many parts; but because my education was in this field, I would like to have a relevant work."(No. 9)

\section{SOCIAL INCENTIVES}

Social responsibility of organizations is one of the reasons for the PPP even without financial expectations. Likewise, this motivation has been mentioned to public service by private sector contributors as one of the motivations for this partnership.

Serving people: Assisting people to enjoy high quality services at affordable prices was also of value. The private contributors chose hospitals located in low-income areas to ease access of residents to cheap and quality services. "Always not discussing money making; of course, it is a matter. No benefactor does this certainly; a benefactor sets up a health center and does charity; but a private company instead of putting its money in the bank to take profit or invest in other area, can invest in service delivery, and besides beneficence, deliver service to a needy person. "(No.11)

Spiritual satisfaction: Occasionally, people work not just for incentives, but more for their intrinsic motivations cited by private sector as incentive for partnership. Spiritual motivation was not discussed by the private sector alone. Quite often, public sector interviewees also referred to the spiritual motivation of the private sector participants to choose this kind of service delivery: "They do not work just for money. Of course, I accept that charity alone may not work in our systems but money is not the first trigger. We have a contractor in a department that we are sure it does not have financial benefit, claiming that I came for benevolence" (No. 12)

\section{ECONOMIC MOTIVATIONS}

Increasing revenue and profitability: Remarkable revenues for the private sector in partnership with the public sector, compared to private activity, are expected partly due to the higher number of patients in the public sector. Moreover, some other benefits for the private sector such as the support of medical university at times of trouble and financial facilities, are some advantages offered by the public sector: "Anyone who invests and buys equipment hopes that his return on investment will be higher than the savings in the banking system. If not, the investor will withdraw his money from the hospital service system, and put it in the bank"(No. 11)

Further participation options in the future: Sometimes, choosing to participate by the private sector is not just for immediate profits, but to gain positive points from the university in order to win profitable and popular proposal bidding in the future and sustain their new partnership. "We also know that he (private partner) does not have a lot of profit, but he wants to compete with and win over the rivals in the next year." (No. 13)

Legal constraints: The restrictions imposed by the law are another reason of the private sector for choosing a public sector to participate, and the individual will inevitably seek such options as an alternative. "They say if it does not have much profit for the private sector, why it invests in the

DOI: http://dx.doi.org/10.4314/ejhs.v30i3.12 
public sector? Well, because of the legal restrictions. For example, when our work is imaging but according to Article 20, the imaging license is not issued, although the patient is available for the private sector, they prefer to choose PPP"(No. 11).

\section{DISCUSSION}

Generally, access to the private sector potentials in providing services is in line with the country's economic policies (30) which need to be carefully monitored, as the public and private sectors alone might not be the best option in providing health services (31).

The current study uncovered various incentives related to both public and private sector. The hospitals' current challenges including poor service quality, shortage of various resources as money, manpower and material, and accordingly, the emerging managerial problems mentioned as the key incentives for the public sector to seek the partnership of private sector. This reason seems highly natural given the various problems the hospitals are facing during current situation. Financial problems are nowadays the daily complaint of the hospitals (32). Moreover, some side effects of Health Transformation Plan including specifically the current cuts in human resource budget and an increase in the number of patients (32-33) in the hospitals necessitated the utilization of private sector capability. As such, the quality $(24,26)$ and efficiency improvement $(26,28)$ and a better access to the medical services (26) were mentioned by other studies as main reasons for PPP.

According to the Constitution, article 44, and the country's sixth development plan, the Ministry of Health was obliged to transfer $10 \%$ of its services to the private sector, though this might not be that common in other countries (34). Health service provision in the country is mostly done by the public sector, and the private sector capabilities are just gradually noticed. However, in some countries, the public sector is not able to overcome the problems solely (35-36).

Personal reasons, rarely acknowledged, refer to the unprofessional relations between the hospital managers and private applicants and sometimes conflicts among managers and their personnel could end in any kind of partnership. Apart from being unethical and unprofessional, this incentive did not concur in findings from other studies. This can be a drawback of PPP and lack of management skills among hospital managers in the study.

Individual, social, economic and legal factors were expressed as the incentives of the private sector. Aside from the financial incentives, the private companies were also seeking to build performance record for themselves. Given the intact nature of the health sector, many companies sometimes preferred to enter into and be known at any price, for instance by social incentives, i.e., providing services to the poor at a less price (11, 23). As such, the spiritual incentives, mentioned just in the current study, albeit is common in charity partnership (37) that is rarely seen for profit-oriented participations.

Profitability, governmental privileges, contract extension claiming previous financial debts, and future windows for participation were somehow similarly echoed by other studies $(22,28)$. Bypassing the existing legal constraints through PPP by private sector was mentioned as an incentive in relation to the public health services (23), and not specifically as to the diagnostic services. Furthermore, long term cooperation to share resources and improve innovation in the public sector (31), and the exchange and transfer of knowledge and skill to the private sector (28) were other incentives for partnership.

For a successful and effective participation, it seems fruitful to explore the incentives of both public and private sectors. It might help partners to shape a proper picture of partnership. This study has cast some light on this aspect of PPP. Other and more studies are required to generate generalizable results.

Given the results indicating for a successful PPP implementation, the authorities should ease or facilitate partnership by designing a framework that assures utilization of private expertise, knowledge and innovation, meanwhile considering financial profits of the private participant, if any win-win approach is going to be adopted. The prominent issue in such collaboration is that, at no price, the quality of services should be sacrificed. 
Further studies could look into the effect of partners' alignment on the success of PPP agreements in diagnostic services.

\section{ACKNOWLEDGMENTS}

This researchers have been supported by Tehran University of Medical Sciences and Health Services Grant No. 95-02-27-30952. Ethical approval for this study was obtained from the Research Ethics Committee of Tehran University of Medical Sciences.

\section{REFERENCES}

1. Kermani B, Gharsi M, Ghanbari B, Sarabi Asiabar A, Atefi-Manesh P, Baniasadi A, et al. The relationship between the levels of patient care and length of stay in hospital. Journal of Shefaye Khatam. 2015;3(3):32-40.

2. Ferdosi M, Farahabadi E, Jandagheian M, Haghighat M, Parnaz N. Outsourcing effectiveness of admission units of imaging centers in Ayat-o-allah-Kashani hospital to non-governmental sector. Hospital. 2011; 10(3):2-10.

3. Slade SC, Philip K, Morris ME. Frameworks for embedding a research culture in allied health practice: A rapid review. Health Res Policy Sys. 2018;16(1):29.

4. Asefzadeh S, Alijanzadeh M, Peyravian F. Out of pocket expenditures for outpatient clinics in teaching hospitals. Payesh. 2014;13(3):267-76.

5. Arab. A, Abbasi AM, Dastyar B. Investigating the important criteria for attraction of private section in construction, equipping and operation of hospitals using public - private partnership model. Hospital. 2016;5(2):11123.

6. Sadeghi A, Barati O, Bastani P, Daneshjafari D, Etemadian M. Strategies to develop and promote public-private partnerships (PPPs) in the provision of hospital services in Iran: a qualitative study. Electron Physician. 2014;8(4):2208-14.

7. Abadie R. Infrastructure finance surviving the credit crunch. London: PWC Public Sector Research Centre Publication. 2008;33-4.
8. Musavi SM, Ahmadi M. Public participation private: Theoretical foundations and case studies. Tehran: Imam Sadiq University;2014:29-38

9. Etemadian M, Shadpour P, Soleimani MJ, Biglar M, Radfar MH, Jarrahi M. An Iranianislamic model of public-private partnership in hospital management: introducing Moheb hospital model. Int $J$ Hospital Research. 2013;2(2):95-8.

10. Delmon J. Public participation - private in infrastructure projects, a key guide for policy makers. Tehran: Research institute of economics; 2015:63-5.

11. Manso L. Water institutions and management in Switzerland. CDM working paper series, Swiss federal institute of technology, scientific production and competences, College of management of technology; 2015.

12. Chong VC. Sustainable utilization and management of Mangrove ecosystems of Malaysia. Aquat Ecosyst Health Manag. 2006;9(2):9-10.

13. Barr DA. Ethics in public health research: A research protocol to evaluate the effectiveness of public-private partnerships as a means to improve health and welfare systems worldwide. Am J Public Health. 2007; 97(1):19-25.

14. Buse K, Waxman A. Public-private health partnerships: A strategy for WHO. Bulletin of the WHO. 2001;79(8):748-54.

15. Pongsiri N. Regulation and public-private partnerships. Int J Public Sec Manag. 2002; 15(6):487-95.

16. Abramson W. partnerships between the public sector and non-governmental organizations. United State: Bethesda, Abt Associate Inc. 1990:88-92.

17. Scharle P. Public private partnership (PPP) as a social game. Innovation-Abingdon. 2002;15(3):227-52.

18. World Health Organization. Public private partnerships: Managing contracting arrangements to strengthen the reproductive and child health programme in India, lessons and implications from three case studies. Geneva, Switzerland.2007:98. 
19. Jalali SG, Shahanghi $\mathrm{K}$, Emamian $\mathrm{S}$. Presentation of financial models in order to solve the dispute in a public-private partnership contracts using game theory. Management research in Iran. 2014;18(3):124.

20. Mossoro M. Opportunism in public-private project finance, IESE Business School. Spain: University of Navarra. 2011.

21. Meier F, Schöffski O, Schmidtke J. Publicprivate partnership as a solution for integrating genetic services into health care of countries with low and middle incomes. J Community Genet. 2013;4(3):309-20.

22. Alsaleh A. Realist evaluation of public private partnerships in the Kuwait health care system. Doctoral thesis, United Kingdom: University of Surrey. 2012;29-31.

23. Krech R, Kickbusch I, Franz C, Wells N. Banking for health: the role of financial sector actors in investing in global health. BMJ global health. 2018;3(1):597.

24. Chen JY, Wan EY, Chan KH, Chan AK, Chan FW, Lam CL. Evaluation of the quality of care of a hemodialysis public-private partnership program for patients with end-stage renal disease. BMC nephrology. 2016;17(1):79.

25. Bennett RJ, Krebs G. Local economic development partnerships: an analysis of policy networks in EC-LEDA local employment development strategies. Regional studies. 1994;28(2):119-40.

26. Ahmed F, Nisar N. Public-private partnership scenario in the health care system of Pakistan. East Mediterr Health J. 2010;16(8):910-12.

27. Ahadzi M, Bowles G. Public-private partnerships and contract negotiations: an empirical study. Constr Manag Econ. 2004; 22(9):967-78.
28. Tičar B, Zajc K. Public-private partnerships in Slovenia: Recent developments and perspectives. Review of Central and East European Law. 2010;35(2):191-215.

29. Hsieh F, Shannon S. Three approaches to qualitative content analysis. Qual Health Res. 2005;15(9):1277-88.

30. Khamenei A. General policy of article 44, the constitution low of Islamic Republic of Iran, Iran: Expediency council. 2005. http://farsi.khamenei.ir/news-content?id=165.

31. Campos KDP, Norman CD, Jadad AR. Product development public-private partnerships for public health: A systematic review using qualitative data. Soc Sci Med. 2011;73(7):986-94.

32. Peykanpoor M, Esmaeli S, Yousefi N, Aryaee A. A review of achievements and challenges of health transformation plan. Payesh. 2018;17(5):481-94.

33. Gorbani-nia R, Khezri A, Kamali S, Ghorbani $N$. Survey of nurses' satisfaction with the health transformation plan at Pastur hospital. Health Inf Manag, 2017;14(3):138-41.

34. Sarmah B. Public-private partnership in health care sector: Issues and evidence. International conference on health for all: Opportunities and challenges. India: Jaipur. Sep 2009.

35. Thadani, KB. Public private partnership in the health sector: Boon or bane. Procedia Soc Behav Sci. 2014; 157:307-16.

36. Zaki M, Hui Lin Ch, Tungsanga K. Funding renal replacement therapy in Southeast Asia: Building public-private partnerships in Singapore, Malaysia, Thailand, and Indonesia. Am J Kidney Dis. 2015;65(5):799-805.

37. Erick F. Oechler S. Public private not-forprofit partnerships: delivering public services to developing countries. Procedia Eng. 2014; 78:259-64. 